\title{
ADSORPTION OF SURFACTANT DISPERSED NANOMETER MAGNETITE
}

\author{
J. Y. HWANG \\ Michigan Technological University, Institute of Materials Processing \\ 1400 Townsend Drive, Houghton, MI 49931
}

\begin{abstract}
Processing of fine particles in a slurry is a difficult problem. Methods to make fine particles magnetic have been developed recently and may offer a solution to this problem. Particles of nonmagnetic materials can be selectively rendered magnetic through surface interactions with magnetic reagents, which are prepared by dispersing nanoscale magnetite (about $10 \mathrm{~nm}$ diameter) with surfactants. When adsorption occurs, the magnetic susceptibility of the material is increased. Magnetic enhancement at several orders of magnitude can be achieved. Selectivity of the adsorption can be controlled by the functional groups of magnetic reagents and various surface interaction mechanisms. This approach allows a new degree of freedom for the processing of fine particles, even with conventional magnetic means. Separation and filtration are examples of the applications.
\end{abstract}

Keyword: nanomaterial, dispersion, flocculation, magnetic reagent, magnetic enhancement, separation. 


\section{INTRODUCTION}

The behavior of fine particles in a slurry is difficult to control, presenting a serious problem for the processing of fine particles in many industries. At fine particle sizes, gravitational force is weak. Electrostatic force, although strong in dry conditions, can rarely be applied for particles in an aqueous slurry. The applications using magnetic force are limited because most materials are diamagnetic to weakly paramagnetic. Without being able to use these forces effectively, the movement of fine particles can hardly be controlled.

There are methods to agglomerate fine particles into flocs, which allows effective applications of gravitational force [1, 2]. Co-flocculation of fine particles with magnetic particles also allows the use of magnetic force [3, 4]. However, these approaches may not be desirable because there are many processes which require fine particles to stay in the dispersed state. Thus, there is a need to develop methods to control the movement of individual particles.

Methods to increase the magnetic properties of fine particles are introduced in this study. Based on the magnetic reagent technology developed at Michigan Technological University [5, $6,7]$, it has been found that magnetic properties of particles can be increased by several orders of magnitude through the adsorption of a magnetic reagent. Thus, a new degree of freedom can be utilized for the processing of fine particles of nonmagnetic materials. Through the use of magnetic means, movement of fine particles with enhanced magnetic properties can be controlled. These particles can be separated, collected, immobilized, or filtered. Many applications can then be developed.

\section{MAGNETIC REAGENT AND ITS FUNCTIONS}

A magnetic reagent is a composite of magnetic materials and surface active agents. The surface active agents contain functional groups which can react with magnetic materials and other materials. Under appropriate conditions, the agents can serve as a bridge to couple magnetic materials to other materials. Thus, the composite of magnetic materials and surface active agents with the capabilities to couple other materials is a magnetic reagent.

In many applications, a magnetic reagent is prepared by building two layers of surfactants on colloidal (nanometer size in most cases) magnetite. The inner layer surfactant has a functional group with an affinity to magnetite. Fatty acid, such as oleic acid, is an example. After covering the surface of magnetite with the inner layer of surfactants, an outer layer surfactant can be built on top of the inner layer surfactant through hydrophobic interactions. The functional group of the outer layer will orient outward from the magnetite and provide the capability for coupling with nonmagnetic materials. Since the functional group of the outer layer can be tailored, selectivity on the coupling can then be controlled. 


\section{ADSORPTION OF MAGNETIC REAGENT}

The adsorption of magnetic reagents on fine particles is similar to the adsorption of surfactants in many aspects. Common mechanisms for the adsorption of surfactants on particles include chemical bonding, electrokinetic force, van der Waals force, and hydrogen bonding. These principles can be applied to control the adsorption of magnetic reagents, although the extent of these forces may vary from the adsorption of surfactant alone. Experiments to verify the adsorption mechanisms have been conducted. Some examples are discussed here.

There are many factors affecting the adsorption of surfactants. In addition to properties inherited with the surfactants and particles themselves, other factors, such as water chemistry, can play important roles through their ability to modify the properties of surfactants and particles. Examples include $\mathrm{pH}$, activators and depressants, material concentrations, etc. These factors were investigated to understand the adsorption of magnetic reagents on fine particles.

Minerals of research grade, including quartz, calcite, kaolinite and pyrite, were ground to -325 mesh for this study. Grinding was carried out in a ceramic mill to avoid magnetic contamination. Kaolinite was prepared with a blender to eliminate oxidation problems, pyrite samples were washed with dilute hydrochloric acid and dried before grinding. After grinding, the product was stored under a nitrogen atmosphere.

The magnetic susceptibility of each mineral was measured with a Johnson \& Matthey magnetic susceptibility balance at 2 kilogauss. The results were: $0.44 \times 10^{-6} \mathrm{cgs} / \mathrm{g}$ for kaolinite, $3.94 \times 10^{-6} \mathrm{cgs} / \mathrm{g}$ for calcite, and $1.46 \times 10^{-6} \mathrm{cgs} / \mathrm{g}$ for pyrite.

The adsorption study was carried out with standard procedures for each test. In each test, a gram of a mineral powder was slurried in $30 \mathrm{ml}$ of deionized water. Sodium hydroxide and hydrochloric acid were utilized to adjust $\mathrm{pH}$. The salinity of water was maintained at $2 \times 10^{-3}$ molar of sodium chloride. A magnetic reagent was added at a dosage equivalent to $0.002 \mathrm{~g}$ magnetite per gram of mineral, unless otherwise stated. After 3 minutes of mild stirring to condition the mineral particles and magnetic reagent, the mineral particles were filtered, dried, and measured for magnetic susceptibility. The degree of adsorption for the magnetic reagent on a mineral was determined by the amount of magnetic susceptibility increase.

Figure 1 shows the adsorption of MR-30 on quartz and calcite. MR-30 is an anionic magnetic reagent using sodium oleate as the outer layer. In the $\mathrm{pH}$ range of this study, calcite, adsorbed MR-30 consistently. Magnetic susceptibility of calcite was increased from $3.94 \times 10^{-}$ ${ }^{6} \mathrm{cgs} / \mathrm{g}$ to $38 \times 10^{-6} \mathrm{cgs} / \mathrm{g}$ at the standard dosage. On the other hand, quartz did not adsorb MR-30 in the $\mathrm{pH}$ range from 5 to 9 . The magnetic susceptibility of quartz at $\mathrm{pH} 9$ was $0.8 \times 10^{-6} \mathrm{cgs} / \mathrm{g}$ after conditioning with MR-30. It is well known that calcite can adsorb sodium oleate through chemical bonding. The adsorption of MR-30 on calcite showed a consistent trend. Quartz is also known for its incapability to adsorb sodium oleate. Experimental results showed that quartz cannot adsorb MR-30 as well. The isoelectric point of quartz is close to $\mathrm{pH} \mathrm{3,} \mathrm{which} \mathrm{may} \mathrm{explain}$ the adsorption at low $\mathrm{pH}$. 


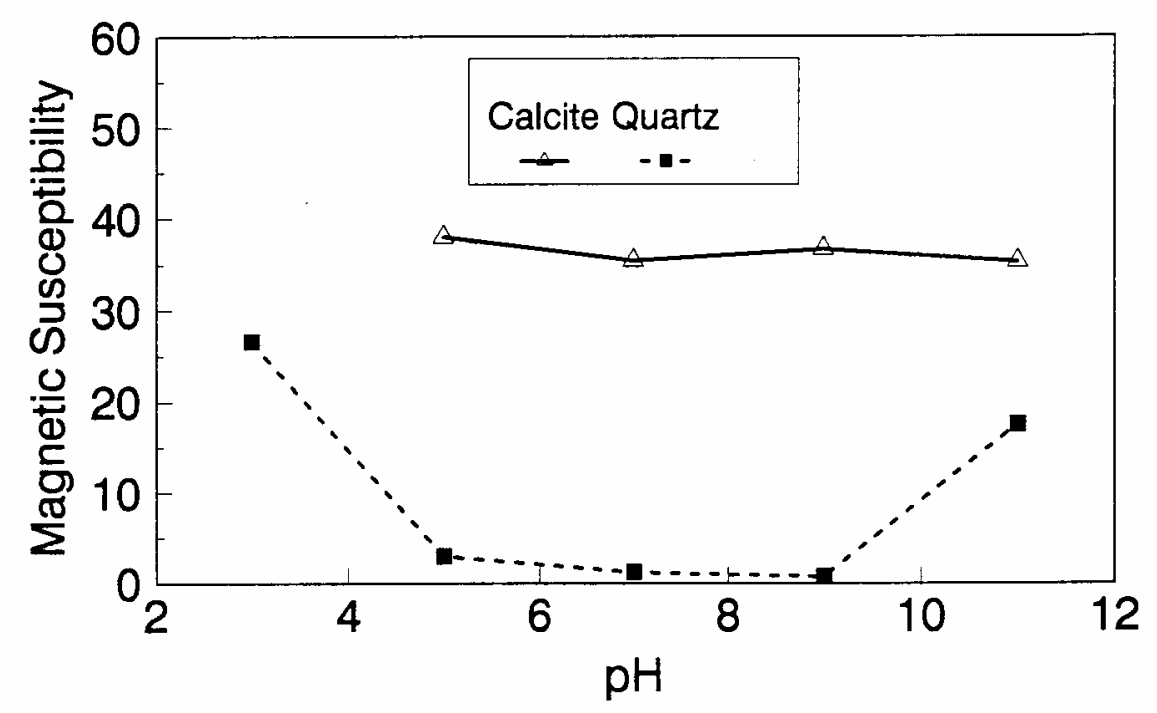

Figure 1. The adsorption of anionic MR-30 (sodium oleate) on calcite and quartz at various pHs.

The adsorption of MR-30 on calcite as various MR-30 dosages is shown in Figure 2. In the range of study, the amount of adsorption was almost linearly proportional to the magnetic reagent dosage. At the magnetic reagent dosage of 0.02 grams magnetite per gram of calcite, the magnetic susceptibility was increased from $3.94 \times 10^{-6} \mathrm{cgs} / \mathrm{g}$ to $437 \times 10^{-6} \mathrm{cgs} / \mathrm{g}$. This demonstrates the strong magnetic enhancement capability through the adsorption of magnetic reagents. 


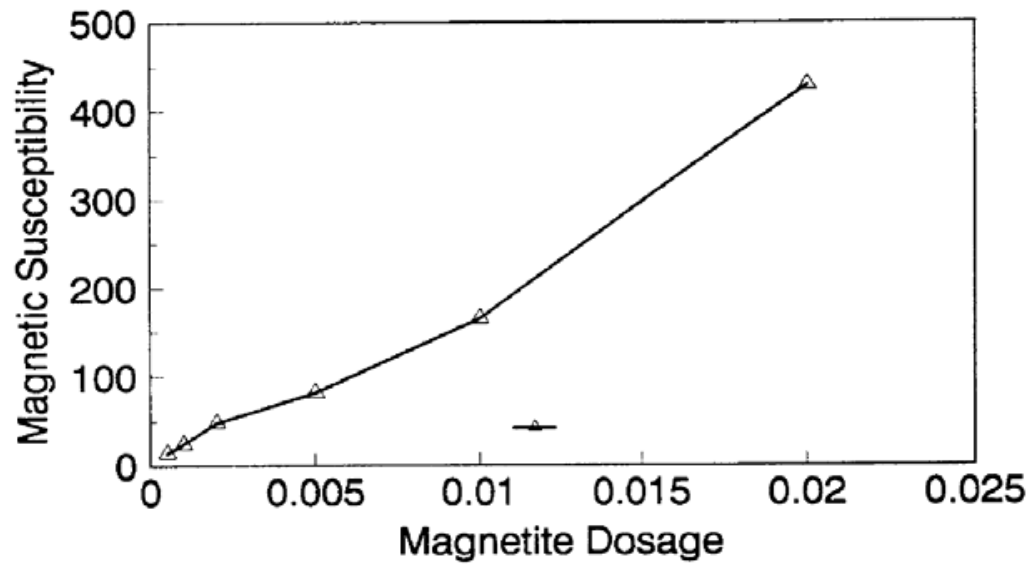

Figure 2. Magnetic enhancement of calcite at various MR-30 dosages.

MR-1 is a cationic magnetic reagent using lauric amind acetate as the outer layer surfactant. The adsorption of this magnetic reagent on quartz, kaolinite and pyrite at standard reagent dosage are shown in Figure 3. Lauric amine is a strong collector for these minerals in the flotation systems. Conditioning of MR-1 with these minerals also resulted in magnetic enhancement. The magnetic susceptibility of quartz was increased from $0.44 \times 10^{-6} \mathrm{cgs} / \mathrm{g}$ to $56.2 \times 10^{-6} \mathrm{cgs} / \mathrm{g}$ at $\mathrm{pH} 3$. The adsorption gradually decreased with the increase of $\mathrm{pH}$. At $\mathrm{pH} 11$, magnetic enhancement is at $30.3 \times 10^{-6} \mathrm{cgs} / \mathrm{g}$. Kaolinite adsorbed MR-1 quite constantly throughout the whole $\mathrm{pH}$ range of investigation. Magnetic susceptibility was increased from $4.84 \times 10^{-6} \mathrm{cgs} / \mathrm{g}$ to $54.9 \times 10^{-6} \mathrm{cgs} / \mathrm{g}$ at $\mathrm{pH} 7$. The adsorption of MR-1 strongly depended on the $\mathrm{pH}$. At $\mathrm{pH} \mathrm{3,} \mathrm{the} \mathrm{magnetic} \mathrm{susceptibility} \mathrm{of} \mathrm{pyrite} \mathrm{increased} \mathrm{from} 1.46 \times 10^{-6} \mathrm{cgs} / \mathrm{g}$ to $22.4 \times 10^{-6} \mathrm{cgs} / \mathrm{g}$ at $0.002 \mathrm{~g} / \mathrm{g}$ magnetic reagent dosage. At $\mathrm{pH} 9$, the magnetic susceptibility increased to $79.8 \times 10^{-6} \mathrm{cgs} / \mathrm{g}$ at the same reagent dosage. The surface charge on pyrite may be responsible for this change

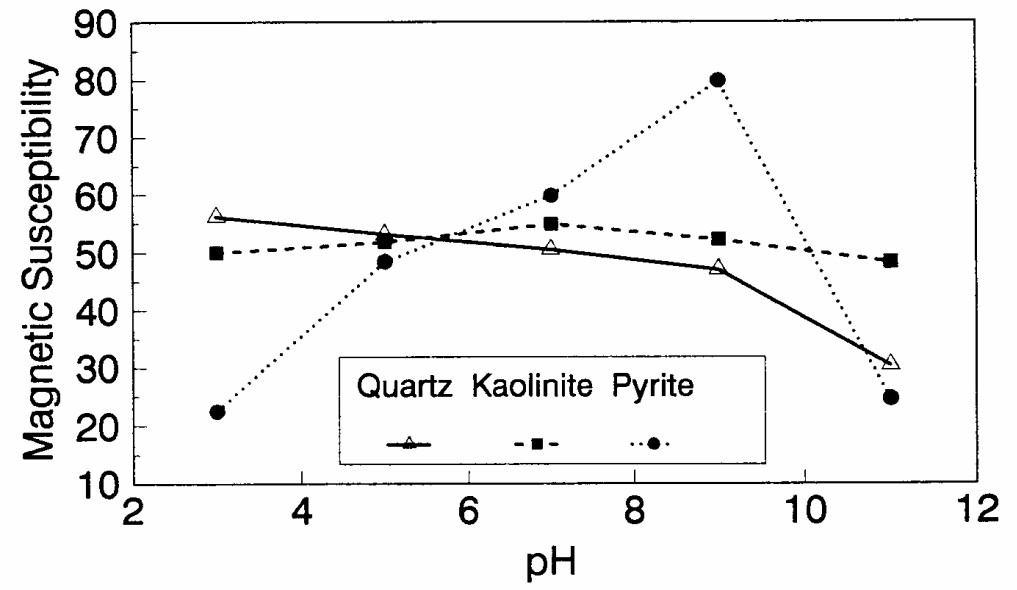

Figure 3. The adsorption of cationic MR-1 (lauric amine acetate) on quartz, kaolinite, and pyrite at various pHs. 
Figure 4 shows the relations between the dosage of MR-1 and magnetic enhancement on quartz. A linear increase of magnetic susceptibility with the increase of magnetic reagent dosage was again observed in the range of investigation. At a dosage equivalent to $0.01 \mathrm{~g}$ magnetite per gram of quartz, magnetic susceptibility was increased from $0.44 \times 10^{-6} \mathrm{cgs} / \mathrm{g}$ to $221 \times 10^{-6} \mathrm{cgs} / \mathrm{g}$.

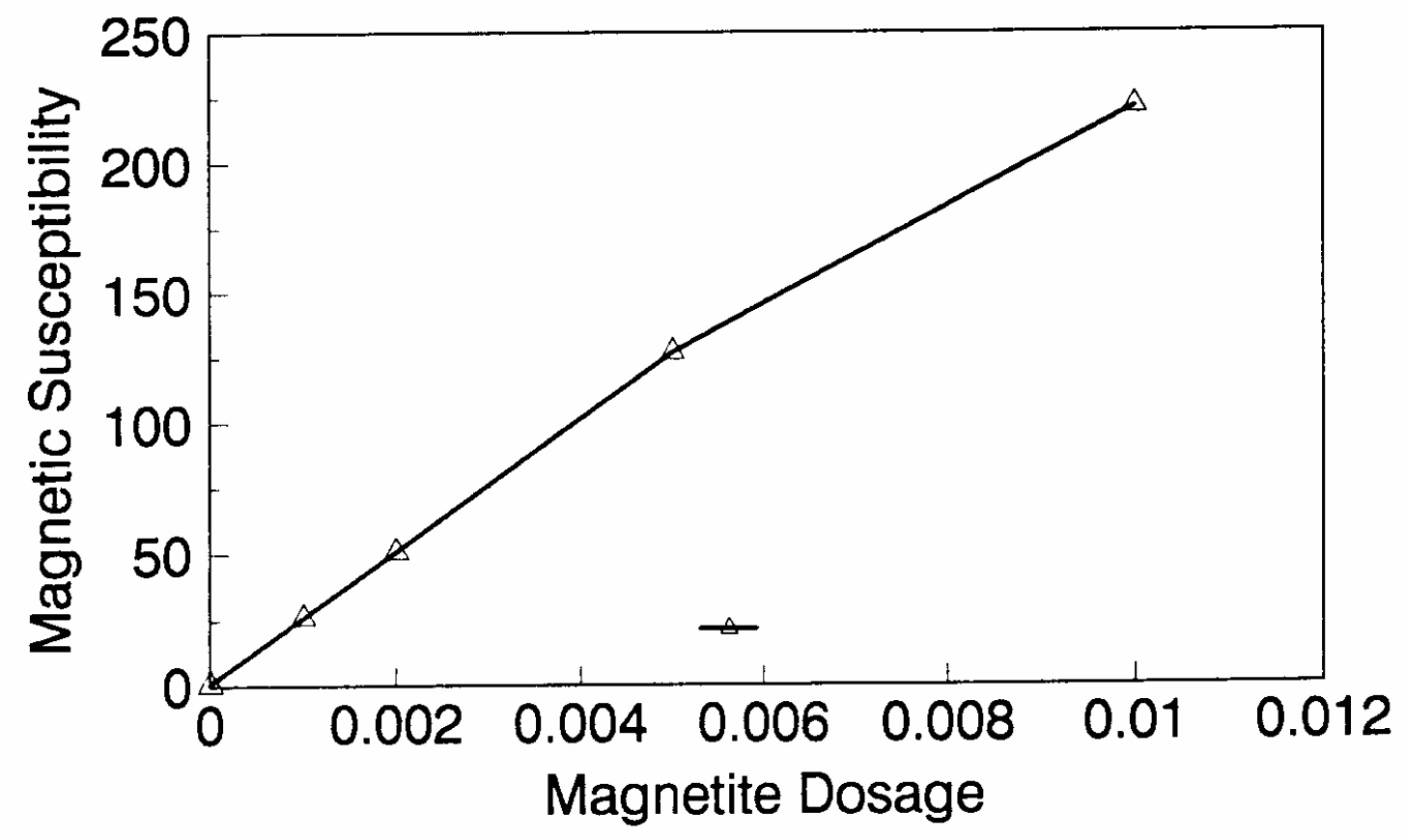

Figure 4. Magnetic enhancement of quartz at various MR-1 dosages.

Nonionic surfactant have rarely been utilized in mineral flotation. However, many nonionic surfactants can be adsorbed on minerals through hydrogen bonding [8], a polyoxyethylene type surfactant is a typical example. MR-45 is a nonionic magnetic reagent employing polyoxyethylene-4 lauryl ether as the outer layer surfactant. The adsorption of this magnetic reagent on quartz, calcite, kaolinite, and pyrite is shown on Figure 5. Quartz showed strong adsorption of this reagent at $\mathrm{pH}$ up to 7 . Hydrogen bonding is believed to be the reason. At higher $\mathrm{pH}$, quartz may have strong negative surface charge and begin to repel the magnetic reagent through the electrokinetic force. Pyrite showed a similar trend of adsorption that may be explained by the same reason. Calcite maintained strong adsorption from $\mathrm{pH} 3$ to 11 because this mineral does not develop strong negative surface charges at these $\mathrm{pH}$ levels. Kaolinite showed a similar trend of adsorption as calcite does. Although kaolinite may carry a stronger negative surface charge than calcite, the high surface area of kaolinite and the van der Waals force may have assisted the adsorption at high $\mathrm{pH}$. 


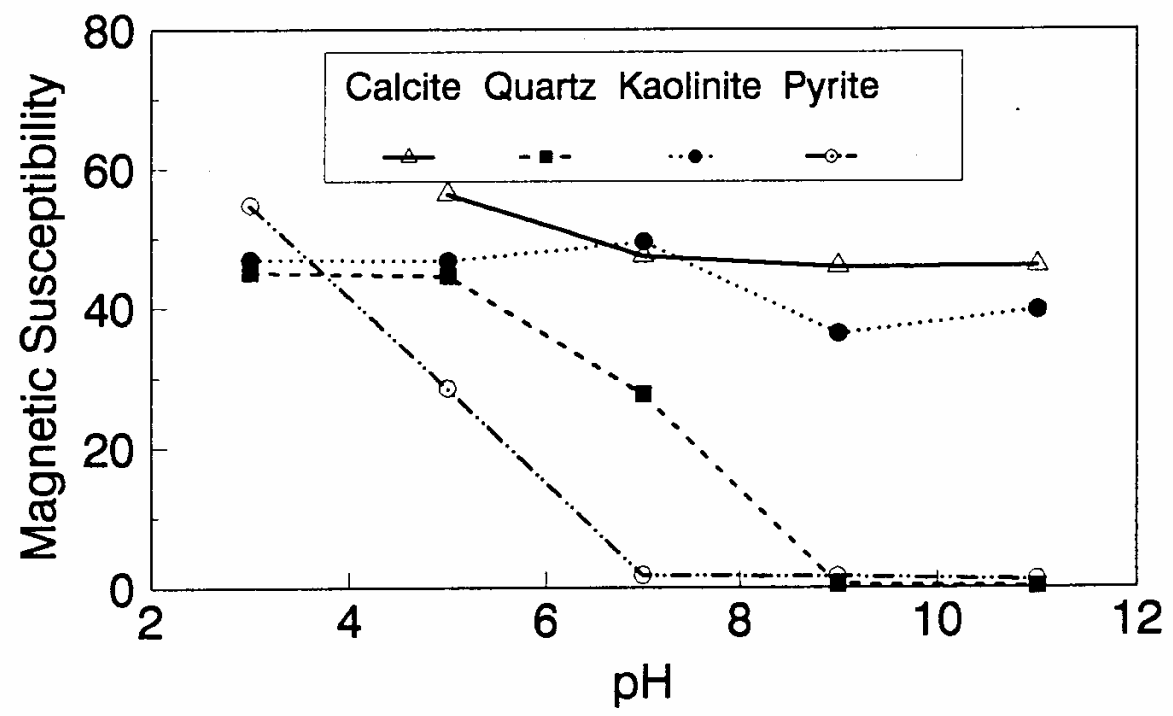

Figure 5. The adsorption of nonionic MR-45 (polyoxyethylene-4 lauryl ether) on quartz, calcite, kaolinite, and pyrite at various pHs.

The adsorption of MR-45 on calcite and kaolinite are quite different when the magnetic reagent dosage is increased. As shown in Figure 6, kaolinite had a linear relationship between the increase of magnetic susceptibility and the increase of magnetic reagent dosage at $\mathrm{pH}$ 7. Calcite, however, had reached a saturation of the magnetic enhancement at a $0.005 \mathrm{~g} / \mathrm{g}$ reagent dosage. Further increase of magnetic reagent dosage had no effect on the magnetic susceptibility. The strength of hydrogen bonding on the two minerals may not be significantly different. Surface area and van der Waals force may have assisted the continuous adsorption of MR-45 on kaolinite at high reagent dosages.

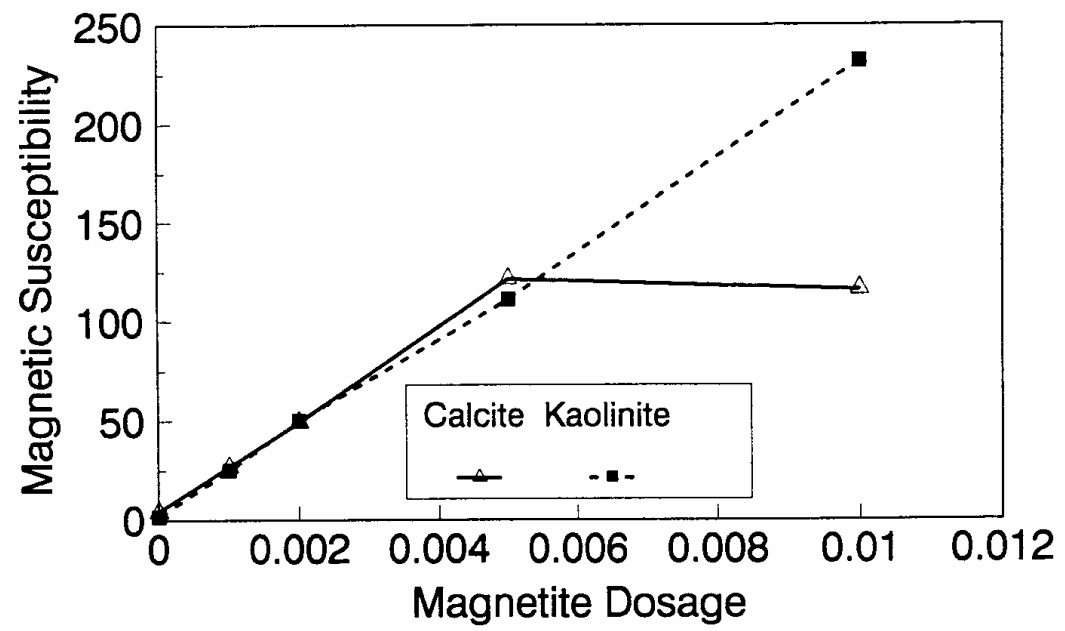

Figure 6. Magnetic enhancement of calcite and kaolinite at various MR-45 dosages. 
The $\mathrm{pH}$ is only one of the factors affecting the adsorption. It functions by changing the surface charge and surface species on fine particles and the solubility and stability of surfactants. Some salts dissolved in water have similar functions. They can activate or depress the adsorption through modifying the surface properties of fine particles and are usually called activators or depressants. Figure 7 shows an example of the activation of quartz for the adsorption of MR-30. Quartz did not adsorb MR-30, which was explained in Figure 1. However, quartz may adsorb calcium on its surface to change its surface properties. The calcium species on a particle surface can then facilitate the adsorption of sodium oleate, which is the outer layer surfactant of MR-30. A series of experiments was conducted to examine this type of adsorption. About $300 \mathrm{ppm}$ calcium chloride was added to a quartz slurry before conditioning with MR-30 following the standard test procedures. The results, presented in Figure 7, show that magnetic enhancement can indeed be achieved with this approach. The stronger adsorption of MR-30 at high $\mathrm{pH}$ was related to the stronger adsorption of calcium. At $\mathrm{pH} 3$, sodium oleate may have been destabilized.

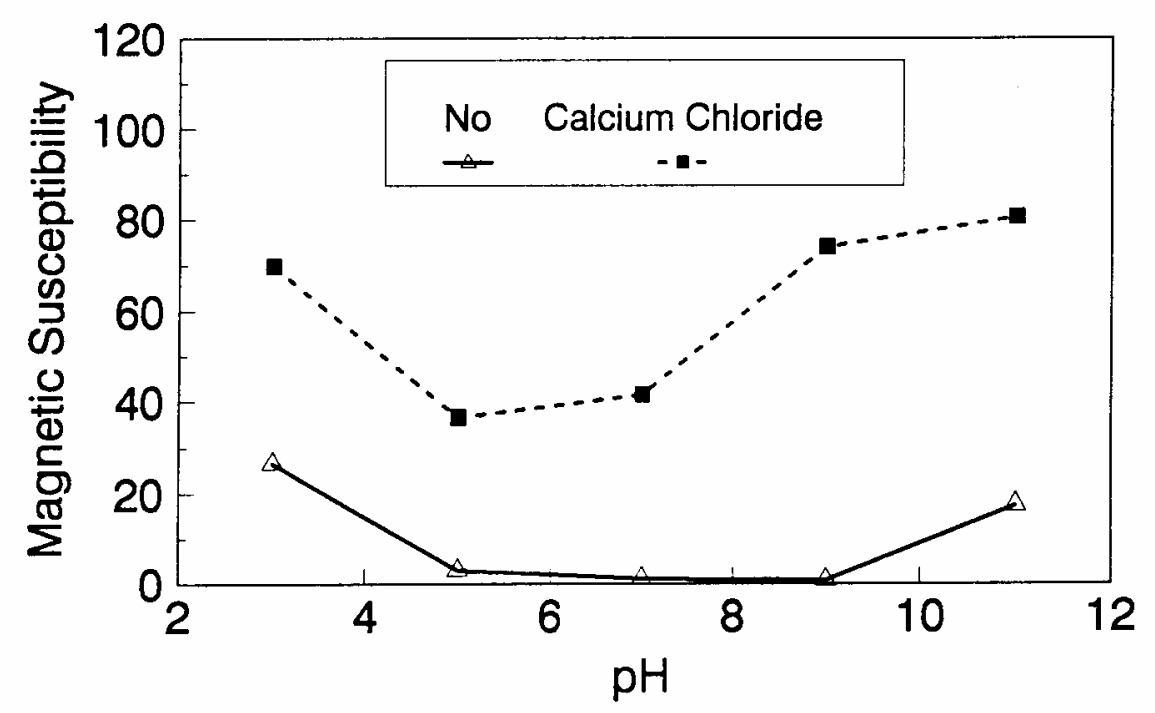

Figure 7. Calcium chloride for the activation of quartz on MR-30 adsorption.

Sodium tripolyphosphate (STPP) is a common depressant for calcite. Adsorption of the anions of this salt on calcite will shield the calcium atoms on calcite and yield a strong negative charge on the calcite surface. The adsorption of sodium oleate on calcite can then be depressed. Figure 8 demonstrates the depressing effect for the adsorption of MR-30 on calcite. By adding 300 ppm STPP to a calcite slurry before conditioning with MR-30, the magnetic enhancement of calcite decreased significantly. With the increase of $\mathrm{pH}$, the depressing effect increased because of the stronger dissociation of STPP. 


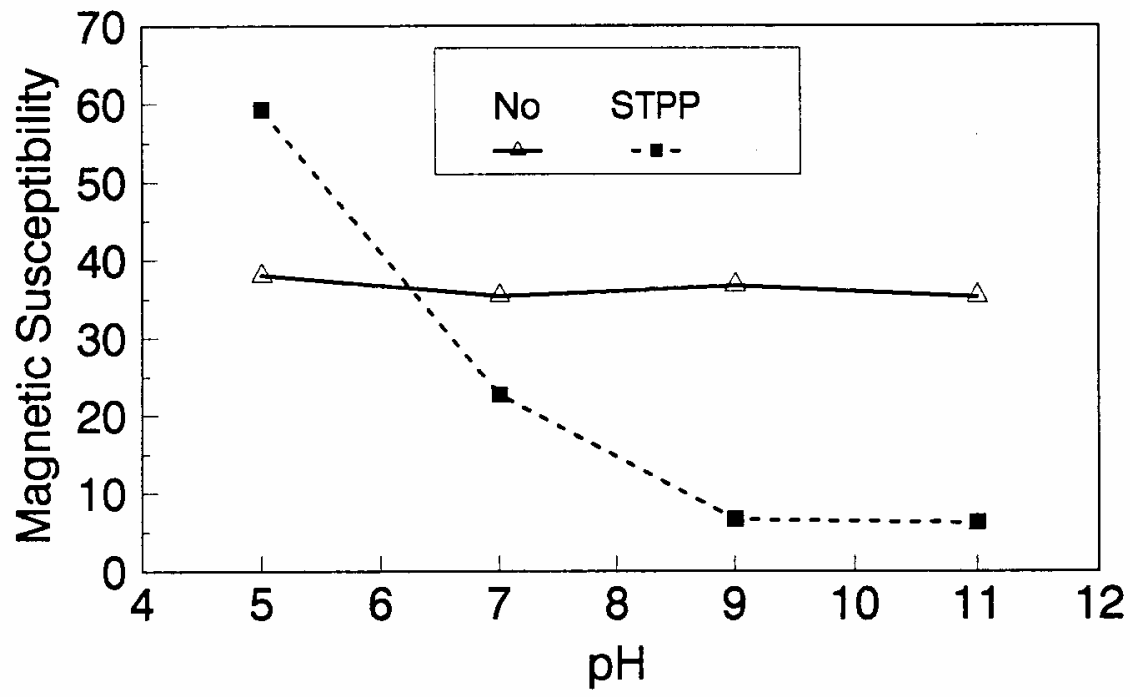

Figure 8. Sodium tripolyphosphate for the depression of calcite on MR-30 adsorption.

\section{CONCLUSIONS}

Using the magnetic reagent methods to make fine particles magnetic is discussed in this study. A model for the adsorption of magnetic reagent is established on the basis of a double layer surfactant structure. The inner layer surfactant has a functional group with affinity to the magnetic nucleus. A second layer of surfactant can be built on the first layer through a hydrophobic interaction. The functional group of the second layer orient outward and can interact with particles. The adsorption of outer layer surfactants on particles will, thus, facilitate the coupling of a magnetic nucleus on the particle to make the particle magnetic. The adsorption of second layer surfactants generally follows the same principles governing the adsorption of surfactants.

Ferromagnetic materials and what are commonly referred to as nonmagnetic (actually diamagnetic to weak paramagnetic) materials generally have a magnetic susceptibility difference of about 6 to 7 orders of magnitude. A very small amount of magnetic reagent adsorption will be sufficient to make the nonmagnetic fine particles processable by common magnetic means. Thus, favorable economics can be obtained for the use of magnetic reagents in many applications.

\section{ACKNOWLEDGEMENT}

The author is grateful to J. Liu, R. S. Kramer, and R. Lizak for their help in carrying out experiments. 


\section{REFERENCES}

1. V.K. La Mer and T. W. Healy, Rev. Pure \& Appl. Chem., 13, 112-133 (1963).

2. R. J. Pugh and J. A. Kitchener, J. Colloid and Interface Science, 35, 656-664 (1971).

3. J. Y. Hwang, G. Kullerud, M. Takayasu, F. J. Friedlaender, and P. C. Wankat, IEEE Trans. On Magnetics, MAG-18, 1689-1691 (1982).

4. J. Y. Hwang, G. Kullerud, F. J. Friedlaender, and M. Takayasu, Soc. Of Mining Engineers of AIME, Transactions 280, 1961-1964 (1986).

5. J. Y. Hwang, U.S. Patent 4,834,898 (1989).

6. J. Y. Hwang, U.S. Patent 4,906,382 (1990).

7. J. Y. Hwang, Symposium of $6^{\text {th }}$ Coal Contractors Conference, DOE, 290-297 (1990).

8. J. Rubio and J. A. Kitchener, J. Colloid and Interface Science, 57, 132-142 (1976). 